\title{
Investigating Iranian EFL learners' writing metacognitive awareness
}

Maftoon, Parviz

English Department, Science and Research Branch, Islamic Azad University, Tehran, Iran (pmaftoon@srbiau.ac.ir)

Birjandi, Parviz

English Department, Science and Research Branch, Islamic Azad University, Tehran, Iran (birjandi@srbiau.ac.ir)

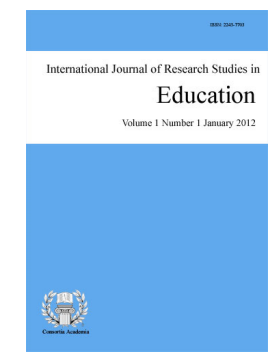

ISSN: $2243-7703$ Online ISSN: 2243-7711

OPEN ACCESS

Farahian, Majid $\square$

PhD student, English Department, Science and Research Branch, Islamic Azad University, Tehran, Iran (majidfa53@yahoo.com)

\section{Abstract}

There has been a growing body of research in the few past decades on the role of metacognition in learning. In line with the evolution of research in the area of metacognition in education, there is a growing need for the better understanding the nature of the construct in foreign language (FL) teaching especially writing skill. In an attempt to develop a model of writing metacognitive awareness, based on both Flavel's (1987) and the two-dimensional dichotomy of knowledge and regulation of cognition (Brown, 1987; Jacobs \& Paris, 1987; Schraw \& Moshman, 1995), 59 English as a foreign language (EFL) learners with different proficiency levels were divided into two novice and expert groups. After writing an essay, the participants took part in a semi-structured interview. The content analysis of the data as well as the related literature revealed a model for Iranian EFL learners' writing metacognitive awareness in which knowledge of cognition with four subcomponents and regulation of cognition with five sub-components emerged.

Keywords: metacognition; EFL writing; knowledge of cognition; regulation of cognition; metacognitive awareness 


\section{Investigating Iranian EFL learners' writing metacognitive awareness}

\section{Introduction}

Writing has always been considered a fundamental skill in education and is regarded as a skill with diverse benefits for the learners in the high-tech world. Success in the academic areas, communication, self-expression, and so on is to a great extent dependent on the mastery of this skill. Being no exception, writing in FL learning is more than a means of communication since it can even help learners learn the FL. Considering such an important role for writing both in first or FL, researchers need to offer their valuable research insights as to the nature of the writing skill and investigate the FL writers thinking process behind it. With such a purpose, process-oriented approaches to writing made speculations about what goes on in the writer's mind when he engages in composing the text. The shift of emphasis from product-oriented to process-oriented approach to writing brought with itself different models of writing notably Hayes and Flower (1980).

Hayes and Flower (1980) as the originators of the first cognitive process-oriented model, devised a model of writing process comprised of three major processes of planning, translation and reviewing each with sub-processes. Writing in Hayes and Flower's model is viewed as problem solving act, therefore, writers "need to keep simultaneously in focus their communicative goals, their writing plans, the nature of the targeted audience, and the conventions of writing" (Wong, 1991, p. 80). This necessitates the importance of a higher order processing since studies of problem solving have demonstrated that metacognition plays a critical role in problem solving (Hawkins, 2007). Although in their schematic presentation of writing process Hayes and Flower (1980) do not make explicit reference to metacognition, what is noteworthy in their model is the role and significance of a higher order process which seems to control cognitive processing. Monitoring in this model coordinates writing processes since it helps the writers set goals, and regulate their progress toward the goals. In fact, such an emphasis on the critical role of metacognition in cognitive models of writing has been so great that Hacker, Keener, and Kircher (2009) define writing as applied metacognition.

During the past thirty years, along with the development of writing theories there have been a great number of attempts to develop the theory of metacognition. Flavell (1979) and Brown, Bransford, Ferrara, and Campione (1983) initiated the first research studies on metacognition. As Flavell (1987) proposes, metacognitive knowledge is "the part of one's acquired word knowledge that has to do with cognitive (or perhaps better, psychological) matters" (p. 21). He divides metacognition into four classes: metacognitive knowledge, metacognitive experience, goals and strategies. Subsequent research, generally agreed by key researchers (Brown et al., 1983; Schraw \& Dennison, 1994; Schraw \& Moshman, 1995), hypothesize that there are two dimensions to metacognition: knowledge of cognition (i.e., what an individual knows about cognition) and regulation of cognition (i.e., how an individual uses that knowledge to regulate cognition).

It has been postulated that metacognition has an important role in second language (SL) / FL language proficiency as well (Flavell, 1979) and it has been found that successful SL learners effectively employ this knowledge to learn the SL (Wenden, 1998). Findings refer to the significant positive correlation between metacognitive growth and performance on the writing achievement. Based on Kasper (1997), the findings have revealed that the ESL learners who received higher scores in their writing tasks are those who have gained higher ratings on all three metacognitive variables, namely, person knowledge, task knowledge and strategy knowledge. Thus, as he concludes, there is a positive correlation between metacognitive knowledge and writing performance of the ESL learners.

In the same vein, Victori (1999) sought the metacognitive knowledge of two ineffective and two effective EFL writers in their writing. As she reports, the ineffective writers' ineptly employed their metacognitive knowledge and they also made limited use of it. Such a scant and limited use of metacognition affected the 
learners' use of strategies. Even, as she maintains, the writing approach and the type of strategy employed by the writer is determined by this knowledge. On the contrary, the effective writers used the person, task, and strategy knowledge more appropriately; consequently, this gave them the ability to make sound decisions. With the same aim of exploring learners' metacognitive awareness, Ruan (2013) explored metacognitive awareness of EFL Chinese writers. Based on Flavell's (1979) framework, he proposed an interactional model of metacognitive awareness in writing encompassing person, task and strategy knowledge. In his model, person, task, and strategy variables are in interaction each involving subcategories. As Ruan (2013) reports, person variable subsumes self-efficacy, anxiety, and motivation. Task variable includes task purposes, task constraints, and cross-language task interference. Strategy variable encompasses planning, text generating, revising, and planning.

The related literature is replete with suggestions on the usefulness of raising learners' awareness and training different kinds of metacognitive skills (Pintrich, 2002). However, it is noteworthy that before starting to incorporate courses in the EFL context for metacognitive instruction, the nature of EFL learners' metacognitive awareness about writing be explored. Although the present study can be considered as a further attempt to delve into metacognitive awareness of writing after Ruan's (2013) study, to the researcher' knowledge, no research study has addressed the metacognitive awareness of EFL writers in writing within the general framework of knowledge and regulation of metacognition.

In sum, with the intention of exploring Iranian EFL learners' writing metacognitive awareness, the present study drew on a pre-hypothesized model of metacognitive awareness for writing which includes both Flavell's and two-dimensional dichotomy of knowledge and regulation of cognition as its point of departure (see Table 1). Based on such a conception, while knowledge of cognition subsumes declarative, procedural, and conditional knowledge proposed by the two-dimensional model of metacognition (Brown, 1987; Jacobs \& Paris, 1987), declarative knowledge is of two sub-branches; person, and task knowledge proposed by Flavell (1979).

\section{Table 1}

The framework for metacognitive awareness writing knowledge

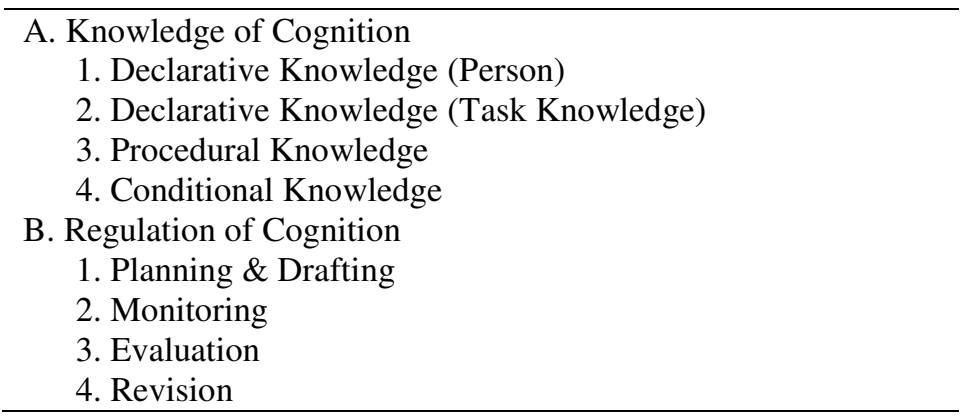

In addition, it was assumed that exploring metacognitive awareness of Iranian EFL learners through interview may contribute to having a better understanding of metacognitive awareness. Having such a purpose, the researchers made an attempt to find out if metacognitive awareness of Iranian EFL learners mirrors the literature. Therefore, the specific questions were formulated:

1. What are the underlying factors of metacognitive knowledge about EFL writing reported by Iranian EFL learners?

2. What are the underlying factors of metacognitive regulation about EFL writing reported by Iranian EFL learners? 


\section{Method}

\section{1 participants}

Of 538 participants originally considered to take part in a separate study intending to develop a metacognitive awareness writing questionnaire, 59 were selected to take part in a semi-structured interview. All participants were selected from EFL Iranian university students. They were majoring various fields of study including Teaching English, Translation and Literature.

\subsection{Procedure}

Out of 538 EFL learners who took the TOEFL proficiency test, 59 subjects were randomly selected to take part in the interview. These participants were of different levels of proficiency and based on the scale developed by Jacobs, Zinkgraf, Wormuth, Hartifiel, and Haughey (1981) they were put into two broad categories of novice and skillful writers. Students with varying degrees of proficiency in writing were selected for the study since the metacognitive knowledge of novice and skillful writers vary in terms of quantity and quality (Victori, 1999). Novice, in the present study, broadly refers to both writers who lack the ability to write in English and those who are less skillful. The category belonging to skillful writers embraced both writers with average ability in writing as well as the experts. Based on the scale, 59 participants were composed of 44 unskilled and 16 skilled writers.

Before being interviewed, the participants were given a timed essay. The reason for giving this assignment was to prepare an appropriate context for the assessment of metacognition (Gunstone, 1994). This could enable the participants to relate their metacognitive knowledge to a concrete task. Next, the interview was held. All the interviews were then recorded and transcribed.

\subsection{Data collection}

In the present study, both inductive and deductive approaches were used in order to analyze the data. As such, at the beginning of analysis, the open coding analysis was adopted by the researchers. Open coding is employed in qualitative research when the researcher approaches the analysis without considering any predetermined framework to sort out the data. After the inductive data analysis was conducted and categories emerged the deductive analysis as the confirmatory stage was adopted. At the next stage, the emerged, categories were compared and contrasted to the two-dimensional model of metacognition (Brown, 1987; Jacobs \& Paris, 1987).

\section{Result}

Based on the research questions, the findings were categorized under two categories: (a) reported categories of knowledge of cognition in writing (see Table 2); and (b) reported categories of knowledge of regulation in writing (see Table 3). These two categories provide answers to two research questions.

\subsection{Knowledge of metacognition}

Self-concept and self-efficacy - Declarative knowledge refers to the propositional knowledge one holds regarding his cognitive skills. Part of this knowledge is the individual's belief about himself and his abilities (Tarricone, 2011; Vanderswalmen, Vrijders, \& Desoete, 2008). As a variable which affects individual's performance and his motivation is his judgment of his capabilities to undertake a task (Bandura, 1982) and as a variable which influences FL learning, self-efficacy was found to play an important role in students' writing. $47 \%$ of novice participants regarded writing as a difficult task and were reluctant to write in the FL. Among these students, $9 \%$ viewed writing as an inborn capability which needs talent. These participants considered writing both in first and SL as a complex skill which needs highly specialized skill. It seemed that these students 
did not have a positive self-concept toward their own abilities since two students from this group reported that they felt bad about themselves when they wrote in English and that writing in English made them appear foolish. One of these students showing a low self-concept toward her writing skill remarked "I do not think I ever master writing English". The rest of the participants who belonged to $47 \%$ above-mentioned participants did not show a positive attitude toward their own capability to write in English and felt that their endeavor did not lead to high quality writing. Interestingly enough, among the novice writers, $11 \%$ were students who based on one of the researchers' experience were of limited English language proficiency; however, they showed a great confidence in FL writing.

\section{Table 2}

Reported themes and categories of knowledge of cognition

\begin{tabular}{lcc}
\multicolumn{1}{c}{ Themes and categories } & \multicolumn{2}{c}{ Instances } \\
\cline { 2 - 3 } & $\mathrm{N}$ & $\mathrm{E}$ \\
\hline 1. Declarative Knowledge (Person) & $47 \%$ & $93 \%$ \\
Self-concept \& self-efficacy & & $44 \%$ \\
General facts and opinions & $45.5 \%$ & $31.5 \%$ \\
$\quad$ Mental translation & $52.3 \%$ & $31.5 \%$ \\
$\quad$ The effect of reading in FL & & $12.5 \%$ \\
2. Declarative Knowledge (Task Knowledge) & $4 \%$ & - \\
Organization of the text & - & $12.5 \%$ \\
Text-type & $73 \%$ & $43.8 \%$ \\
Linguistic resources & $4.5 \%$ & $4.6 \%$ \\
Topic familiarity & $4.6 \%$ & $2.3 \%$ \\
3. Procedural knowledge & & \\
4. Conditional knowledge & & \\
\hline
\end{tabular}

Note. Instance refers to frequency of codes related to each category

93\% of the experts were positive regarding their writing ability in English; however, it seems that apart from the students' self-concept, the type of the written task affected their level of self-efficacy. In this regard, $12.5 \%$ of participants stated that although they were sure about their overall ability in writing in English, the complexity of the task and their judgment of whether they can do it depend on the type of the task. As one of the skillful participants stated, "if I'm required to write a letter, I feel more secure than when I'm given cause and effect essay". All in all, although self-concept and self-efficacy seemed to play an important role in learners' writing, learners' self-concept and task type affected their level of self-efficacy.

General facts and opinions - There is no agreement among scholars as to whether beliefs are part of learners' metacognitive awareness. As an epistemological debate, cognitive psychologists like Favell (1987) assume that one's epistemology directs and influences his thinking and learning. According to such a perspective, as Bernat and Gvozdenko (2005) argue, metacognition which encompasses one's knowledge of his thinking and learning subsumes individual's beliefs regarding themselves and the world. In contrast to this perspective, Wenden (1999) argues that beliefs are value-laden and as such are not part of the individuals' metacognitive processes. The present study takes side with cognitivism and recognizes one's belief as regulating and shaping one's metacognitive mechanism into acting in one way or another. As such, it is assumed to be a subcategory of declarative knowledge. For this reason, learners' belief regarding what good writing in general is and what difficulties EFL writers may encounter while writing is reported in a separate category.

Mental translation is an inevitable process in FL writing. Those learners who engage in mental translation transfer linguistic and schematic knowledge from their L1 to the FL (Leonardi, 2010). Mental translation, though deemed as beneficial by few participants, was regarded as the main problem an EFL writer encounters while composing in FL. Participants were aware of mental translation. $45.5 \%$ of novice writers recognized mental translation as a barrier to learning. As one of the novice students declared, "[mental] translation was the reason she wrote English with Persian structure". $25 \%$ of experts had the similar view regarding the effect of first language in writing and expressed negative view regarding translation suggesting that thinking through English 
Maftoon, P., Birjandi, P., \& Farahian, M.

deprives an EFL writer of having a native-like writing.

On the contrary, $19 \%$ of expert writers regarded mental translation as a strategy for planning and generating their ideas. "I resort to outlining the content in Persian and writing some phrases in my first language [regarding what should appear in the text]. As to what helps one think through the SL, one of the expert writers expressed that mental translation is unavoidable; however, practice in reading English may help them use English structures. It seems that both for novice and expert writers the concern was the negative effect of mental translation on syntax.

Reading in FL was addressed by the participants as being very influential in effective writing. The literature has demonstrated that extensive reading has a positive impact on language learners' writing skill (Chuenchaichon, 2011; Tsang, 1996). It seemed that the majority of the students were aware of the influential effect of reading the SL on writing. $52.3 \%$ of the novice and $31.5 \%$ of the experts admitted that reading in FL contributes to enrichment of one's linguistic resources, their familiarity with mechanics of writing, and enrichment of the content. While novices favored reading for its contribution to improvement of vocabulary and grammar as well as mechanics of writing, experts valued reading for its effect on the both vocabulary growth and content.

Declarative knowledge (Task knowledge) - Information about the task and task demands can be categorized under declarative knowledge (Tarricone, 2011). With regard to task awareness, the themes in the present study were related to the students' awareness of the nature of the task, and the demand for the skills to do the task.

Regarding the nature of the task, organization of the task was a recurrent theme. $4 \%$ of novices and $31.5 \%$ of experts believed that familiarity with introduction, body and conclusion was necessary for a good piece of writing. Despite such awareness, when novices were asked about the format of introduction, body and conclusion, they did not provide vivid explanations. Experts, apart from the pattern of introduction, body and conclusion referred to thesis statement in the essay and its importance in organizing the whole text. Yet, some of the skillful writers were not fully aware of the importance of each step of the format.

Text-type familiarity was the next theme which the expert students were aware of. $12.5 \%$ of skillful writers highlighted the importance of text-type in EFL writing. One skillful writer expressed doubt to regarding their ability to write satisfactorily based on the unfamiliar genres. She noted that "writing an email to a friend is not the same as writing a scientific essay". Another skillful writer put emphasis on being exposed to some texts as models if they were supposed to write particular text types. It should be mentioned that modeling as a composing strategy (Riazi, 1997), is a strategy employed by SL writers "to look for appropriate genre for writing" (Mu, 2005, p. 8).

As to the necessary skills required to perform writing tasks, high priority was given to vocabulary and its role in writing. Not surprisingly, a lot of EFL learners were preoccupied with linguistic resources particularly vocabulary. It was evident that the problem which concerned the participants was lack of knowledge of vocabulary items. $73 \%$ of novices emphasized enlarging their vocabulary; however, it seemed that they overemphasized the role of vocabulary in writing and considered vocabulary knowledge as the most important element contributing to their proficiency in writing.

Apart from the role of grammar, topic familiarity was expressed as the needed skill by $4.5 \%$ of novices and $12.5 \%$ of experts. As one of the novice students expressed, "the type of topic is imposed by the teacher, [then] no matter how easy the task would be I would easily give up". Another novice writer addressed topic familiarity when she remarked "when I begin writing, the first question which comes into my mind is if the topic is familiar". Thus, the novice writer expected some degrees of familiarity with the topic. As another unskillful writer added, unfamiliar topics for which the teacher has had no prewriting activities "is one of the worst type of topics". 
Procedural knowledge and conditional knowledge - Procedural knowledge is defined as the individual's awareness regarding how to apply strategies (Harris, Santangelo, \& Graham, 2010). Equipped with procedural knowledge, the individual knows how to deal with a particular goal. Conditional knowledge, on the other hand, pertains to why and when of strategies. Thus, it gives the individual the direction as to helps the individual "to determine the appropriate conditions in which to apply procedural and declarative knowledge" (Harris et al., p. 228).

In response to the question "do you know how to begin, proceed and conclude the writing task?" it was evident that some of the students had a vague understanding of their writing process and regarded writing as one shot effort. $27.3 \%$ of novices had such a view. Having such a perspective in mind, one of the unskillful writers expressed "When you get started, ideas flow and you need not to get worried about the text". There were others, about $25 \%$ among novices who referred to activities such as looking up the needed words in a dictionary before starting to write, reading each paragraph carefully for spelling and grammatical problems as necessary steps in writing. Among the unskilled writers only $4.6 \%$ could give examples of strategies and explain why they used them. In contrast, although initially skillful writers had no clear idea of strategy, $43.8 \%$ could provide examples of some in the process of composing. All in all, steps in the writing process frequently referred to were brainstorming, planning, outlining, preparing a draft, getting help from either a model or texts available in the Web, as well as checking for spelling, vocabulary, structure and revision.

Only a few students provided the account of awareness of their conditional knowledge and those who did were specific regarding the conditional awareness regarding writing. That is to say, they were not able to talk about their conditional knowledge since it seemed to be too much abstract for them. Regarding conditional knowledge, for a large number of students it was evident that they were not aware of the strategies they employed and what they did during writing was based on the idea that writing is transmission of ideas from memory on the paper. There were others who displayed awareness of strategies. They reported under what circumstances they used a particular strategy, why they employed the strategy, and whether they got help from others as well as resources. A few participants even could explain if they were aware of when and why they used particular strategies. That group of students, including $18.7 \%$ experts and one of the novices, who showed awareness of writing procedural knowledge could describe when they used planning, drafting, monitoring, revision and editing. However, there was discrepancy among the answers. While some monitored at the sentence level and did it after writing down each sentence on the paper, a few did monitoring at the discourse level and did not care for spelling and lexical errors. As for revision, those who revised the texts preferred to do the revision either after composing the text or sometime later.

The findings also showed a gap as indicated in the literature (e.g. Roca Delarious et al., 2002) between students' declarative knowledge from one hand and their procedural knowledge as well as conditional knowledge on the other hand. There were students among both novice and experts who were aware of strategies; however, they were not able to state why they employed the strategy. For example, after a student who belonged to the participants labeled skillful gave a lengthy explanation regarding using thesis statement, she was asked to explain how and under what circumstances she uses thesis statement the participant was unable to present something more than the definition of thesis statement.

\subsection{Knowledge of metacognition}

Planning and drafting - Although the students, 61.4\% novices and 69\% experts, generally agreed that planning was an effective strategy, not all students applied planning in their compositions. This was astonishing since when the students had been asked if they were aware of the steps which they take while writing in FL planning, majority of the participants highly valued planning as an effective strategy. When the participants were asked if they had any plan before writing and were required to explain how they planned, various answers were provided. Some students did not do any planning. One of these students explained, "Before I start to write, I wait for ideas to flow. Nothing I can do but wait". The other student self-assuredly declared, "If the topic is interesting 
Maftoon, P., Birjandi, P., \& Farahian, M.

and if I am given enough time, ideas develop by themselves. What I need to do is having concentration and writing the flowing ideas down on the paper".

\section{Table 3}

Reported themes and categories of knowledge of regulation

\begin{tabular}{lcc}
\hline \multirow{2}{*}{ Themes and categories } & \multicolumn{2}{c}{ Instances } \\
\cline { 2 - 3 } & $\mathrm{N}$ & $\mathrm{E}$ \\
\hline 1. Planning and drafting & $61.4 \%$ & $69 \%$ \\
Audience consideration & $4.5 \%$ & $6.25 \%$ \\
2. Monitoring & $27.3 \%$ & $25 \%$ \\
3. General online strategies & & \\
Budgeting time & $6.9 \%$ & $12.5 \%$ \\
Avoidance & $7 \%$ & - \\
Attention & & \\
Asking for help & $11.5 \%$ & $6.25 \%$ \\
Translation & $34 \%$ & $12.5 \%$ \\
4. Evaluation & $56.8 \%$ & $75 \%$ \\
5. Revision & $47.8 \%$ & $81.25 \%$ \\
\hline
\end{tabular}

It is important to note that when the students who did planning were asked if they stuck to their plan, one of the skillful writers stated that "when I was not proficient enough [in English] I prepared an outline but the problem in sticking to that was my poor vocabulary and grammar". This might suggest that being aware of the strategy does not guarantee its use.

Those students who did planning did not follow the same procedure. Since there is no consensus over who benefits from this strategy, and what type of planning is most effective (Manch'on \& Roca de Larios, 2007), the interview tapped the following characteristics of planning in students' responses. Table 4 represents the medium, the type of strategy for planning, the occurrence of planning, the scope, and the constraints involved in students planning.

\section{Table 4}

Characteristics of planning

\begin{tabular}{ll}
\hline \multicolumn{1}{c}{ Characteristics } & \multicolumn{1}{c}{ Condition } \\
\hline Medium & Persian /English \\
Occurrence & Before getting started/while writing/before and during writing \\
The strategy employed & Mental/ some notes/a sketch/an outline \\
Scope & Global/ local \\
Constraint & Time/interest/proficiency \\
\hline
\end{tabular}

While some participants including $11.5 \%$ of novices and $6.5 \%$ of experts reported that they carried out the planning in Persian, a few, 2.5\% from novice and 31.5\% skillful writers, preferred English as the medium for planning. The detailed description of the type of language as the medium for planning revealed that appealing to first language helps the students organize their ideas and plan them in a shorter time.

The type of strategy the students used for planning varied. There were students from both groups of novice and expert writers who did the planning in their minds. They explained that they were often engaged in mental planning during writing. There were some other participants, among skillful writers, who wrote down some sporadic notes to plan their writing. Others, including 2 experts, preferred either preparing a sketch or the outline. Notes and outlines gave them the idea regarding what were the major points to be written. This included the main theme and the main points which to be discussed.

Some novices did not have any planning at all. Others, who adopted the strategy, did it while writing. Moreover, they repeatedly revised their plans. Experts planned before and/or during writing; however, it was reported that if they write in the classroom, the time allocated by the instructor was critical in planning for the 
skillful writers. More time resulted in better quality of planning and less changes in the original plan. Experts also involved in global planning. After they made their original plan of what they were going to write, they made little adjustment in it. In sharp contrast, less skilled writers tended to make frequent adjustments as if they were unsure of what they were doing.

Interest as well as the communicative function of the composition was another factor which constrained students in adopting planning. As one of the novice students put it, "if I write something as an assignment, I do it with no planning in advance [but] writing an email to a real person is another matter". Similarly, language proficiency seemed to affect learners' planning since some learners explained that because of their poor proficiency in English they preferred not to prepare any outline. One of the novice students stated that "I' $m$ so worried about suitable expressions that I do not think planning may help me'. However, conclusion may not be drawn that poor proficiency necessarily leads to abandoning this strategy.

Audience consideration - Awareness of audience is a characteristic of skillful writers (Yu-Ling \& Shih-Guey, 2001). Before and while writing they keep in mind that they are writing for a real audience and they have a purpose. In educational settings where writing is part of the curriculum, unless instructors create a communicative context for EFL learners to communicate with real people and write with real purposes in mind, learners have no choice but to have a final product to deliver to the instructor. Accordingly, in such a context having real audiences in mind is far cry from the reality. Predictably, only $4.5 \%$ of unskillful writers expressed that while writing they considered the audience in mind. For other novices, conceptualizing an audience was far beyond their imaginations and completion of the task was their main goal. It seemed that audience consideration was aroused based on a real need and was supported by the learners' previous goal-setting behavior in similar conditions. Among the experts, only one participant who was a secretary of an international corporation showed awareness of the audience. Others did not show a keen sense of the audience.

Monitoring - Monitoring as the ongoing evaluation of "one's learning or strategy use" (Shraw \& Dennison, 1994, p. 475) is one of the higher order mechanisms which regulates the process of learning. The content analysis of the themes revealed that monitoring may occur at either linguistic or content level. In response to the questions whether students stop while writing and ask themselves how well they were doing, the running theme was checking the language; however, a few novices referred to checking the content and making sure if they were on the right track. It was also revealed that monitoring may affect the strategy use by the learners. When asked whether they stop while reading and ask how well they were doing, $25 \%$ of skillful writers implicitly referred to the strategies they employed "I check my outline. I check if the way I have outlined has been effective".

$27.3 \%$ of unskilled writers demonstrated awareness of monitoring. Based on the interview data, it was also found out that some novice writers overuse monitoring. Overusing occurred when unskillful writers monitored their linguistic recourses such as checking the vocabulary or sentences. This was in the form of stop-read again-check.

General online strategies - Based on content analysis, students showed awareness of some strategies which did not belong to the subcategories of regulation of condition, hence impossible to be categorized; however, it seemed that these strategies affect the application of other regulatory strategies. As such, budgeting time, use of L1, attention, avoidance, and help seeking were put under the heading on-line strategies. On-line here literary implies the strategies which in one way or another affect the use of other strategies in FL writing and may be in operation while the learner is using other strategies.

Among all other factors, application of effective writing strategies depends on the writer's management of time as part of the self-regulatory behavior (Zimmerman \& Risemberg, 1997). Management of the allocated time was one of the recurrent themes. $6.9 \%$ of novices and $12.5 \%$ of skilled writers referred to the importance of management of time and claimed they budget it in the process of writing. It was evident from what they mentioned that some strategies were not employed when the students ran short of time. For example, for experts, 
planning and revision were negatively affected if the student felt she did not have enough time to adopt the strategy. It seems that for novice students estimating and budgeting time was greatly influenced by their insufficient linguistic resources. As one of the novice writers acknowledged, while writing he was so exclusively concerned with appropriate words that the he ran short of the estimated time.

Although there is no agreement among scholars over the degree of consciousness involved in metacognition (Cary\& Reder, 2002), it seems that metacognition involves both the individual's deliberate decision and his automatic implicit processes (Sun \& Mathews, 2002). It should be noted that deliberate decision does not necessarily imply consciousness as McKeown and Beck (2009) argue. As such, effective application of writing strategies depends on degrees of writers' awareness (Harris et al., 2010).

Since consciousness may not be easily verbalized, no question regarding students' consciousness over writing was asked. Moreover, what could be inferred regarding the participants' metacognitive awareness only includes their explicit awareness of the task. Based on the recorded interviews, novice writers allocated their attentional resources to lower-order processes in their writings. What some of these students reported as to metacognitive processes indicated that based on wild guess they could give information in the form of declarative knowledge; however, they showed no awareness of the regulatory processes. It might be the case that the writers' attention to lower-order processes may have kept them from attending the higher order cognitive functions or they had not developed the executive functions necessary to monitor the writing process. This is in line with Negretti's (2012) finding which suggests a relationship between degree of awareness and type of regulatory function in writing.

Avoidance as a strategy to overcome difficulties in writing is identified as one of the cognitive strategies (Wenden cited in $\mathrm{Mu}, 2005$ ). $7 \%$ of less-skilled participants showed awareness of avoidance and acknowledged that the strategy affected their choice of vocabulary and structure. "I choose those words I'm familiar with. When I have difficulty finding the suitable word, I avoid it. Of course this [avoidance] also happens when there is a problem with grammar". One of the novice students admitted that she adopted topic avoidance and avoided presenting complicated ideas "you might feel you are caught in the trap if you write philosophically, then, I avoid it". When asked if she considers the strategy as a disadvantage she answered "no, there are simple ways of doing things".

Help seeking can be considered as a metacognitive strategy in problem solving. As Newman (1998) argues, students who are aware of the degree of difficulty of the task and at the same time aware of their own shortcomings in their writing may seek help. Diverse resources were reported by the participants for getting help. Both novice and experts showed an awareness of help seeking strategy. Teacher, other classmates, and Web were among the resources they sought help. $4.5 \%$ of novice writers claimed to get help from various sources to find appropriate words. $7 \%$ of novices also sought help when they were challenged by a difficult topic. In this case, students asked the teacher or classmates for clarification or more explanation. Among the experts, one student explained that when the topic is challenging, he gets help from web by modeling similar text.

Use of first language in SL writing is a common practice among the learners (Sasaki, 2002). A glance at Iranian EFL learners' compositions reveals that they resort to Persian while writing in English. Translation or first language was a strategy reported to have both negative and positive effects on students' writing although both novice and experts in the study complained that their writings did not sound English since they believed that they engaged in back translation. There was the common belief among the participants that the more one indulges himself in reading authentic text, the more native-like sentences he would produce. $34 \%$ of novice writers reported that they made use of their first language to translate word by word.

Despite such complaints, the content analysis revealed that translation was reported to be useful in some cases. A novice writer relied on her first language to prepare the first draft of writing. She reread her already-written texts and had self-talk while writing. This, as she reported, helped her organize her mind. Experts relied on their mother tongue to generate ideas, and revise the text. Having self-talked in L1 was also reported by 
$12.5 \%$ of the expert writers.

Evaluation and revision - The reviewing process is divided into evaluation and revision (Becker, 2006). Revision may accompany evaluation in that after the writer carries out an appraisal of the text and gets insights from his evaluation he may set out to refine the text (O'Malley\& Chamot, 1990). 56.8\% of novice writers evaluated their texts. They did the evaluation throughout writing the whole text. For them, evaluation meant rereading the text at the sentence level and concentrating on the surface structure. On the contrary, $21 \%$ of novices indicated that they did not evaluate what they had written. Perhaps, the mixed result was due to the fact that this group of students conceived evaluation just as a global appraisal of the text. The reason for abandoning the strategy, as they declared was twofold; they either did not know how to evaluate or evaluation for them only meant a general appraisal of the text forming either a positive or a negative attitude toward their texts. Apart from checking the mechanics of writing, evaluation served other purposes for expert writers. $75 \%$ of these students evaluated the texts generally to make sure if it was satisfactory in terms of satisfying the teacher, communicative purpose, the content, planned goals, and language used.

Metacognition plays a significant role in revising (Wong, 1991) and may result in editing what has already been evaluated as faulty by the individual. $47.8 \%$ of novice writers and $68.75 \%$ of experts were concerned with revision. The revisions were generally of two types; they did the revision either while writing as a recursive process (Kietlinska, 2006) or it took place after completing each part of the writing task. In the recursive process, students engaged in writing, reading, and editing the text. In contrast, there were students who tended to do the revision after writing a whole paragraph or the whole essay.

As expected, novice writers revised surface level features while skillful writers did revision for mechanics of writing as well as the content, organizing or reorganizing the whole paragraph. Revision for novice writers was in the form of reading and rereading the composed sentences to check surface level features, crossing out the inappropriate vocabulary item and rewriting the incomplete sentences. Skillful writers acknowledged that if they were given intervals to revise their texts, for example a day or more, the quality of their writings would improve.

However, the unanswered question in this study is which type of revision leads to improvement of writing quality. Perhaps, the way the students approached revision was based on the purpose of the task. $8 \%$ claimed that if they write essays to hand them in to their teachers, they do not revise the text. In this regard one of the students explained that "I prefer to hand in the paper as soon as possible if I'm doing it in the classroom or if I'm taking the writing exam. If I write a letter to be sent to a real person, then, I'll revise the text". This comes as no surprise since as Kietlinska (2006) argues, for the learners who tend to undertake the painstaking job of engaging in the correction of surface level structure revision is not rewarding. This may indicate that lack of motivation or self- concept may hinder revision. Moreover, task type with a communicative purpose may induce more revision on the part of the learners.

\section{Discussion}

The present study was an attempt to present a model of writing metacognitive awareness for Iranian EFL learners. Having such a purpose, both unskillful and skillful EFL learners with varying degrees of proficiency were interviewed. The findings (see Table 5) on knowledge of cognition revealed that four subcomponents of declarative knowledge, procedural knowledge and conditional knowledge constitute Iranian EFL writers' knowledge of cognition in writing. Regulation of cognition, as the findings suggest, consist of five subcomponents of planning and drafting, monitoring, general on line strategies, revision, and evaluation.

The findings are congruent with the account of metacognition with two general components (Brown, 1987; Jacobs \& Paris, 1987). Although these two components are interrelated (Brown, 1987; Schraw, 1998), the students' reports indicated that knowledge and control are two distinct elements. In fact, as stated in the results, there were cases, especially among novice learners who were well aware of the cognitive processes of writing but unable to monitor and control the processes. Perhaps, better performance of skillful writers in this study 
Maftoon, P., Birjandi, P., \& Farahian, M.

among other factors could be attributed to their regulatory skills.

\section{Table 5}

The framework for metacognitive awareness writing knowledge

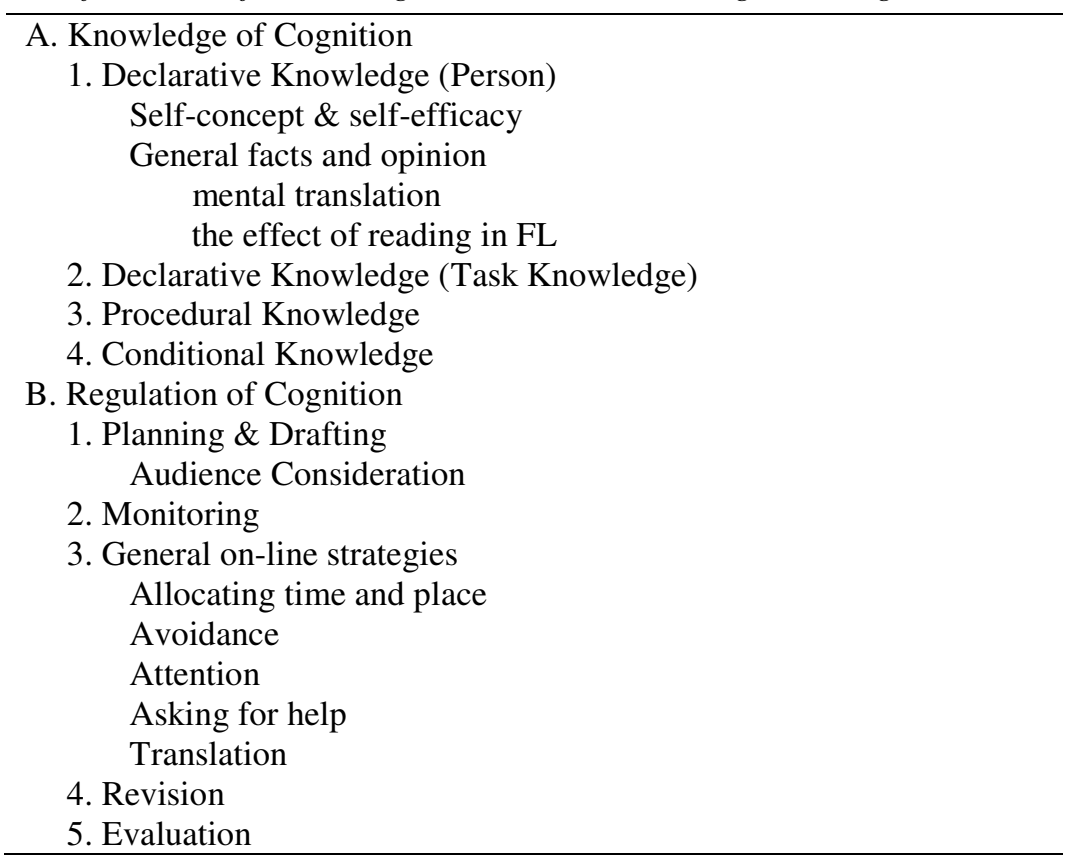

Additionally, the findings of the study suggest that three subcomponents of metacognitive knowledge labeled as declarative, procedural, and conditional (Shraw \& Moshman, 1995) well suit Iranian EFL learners; however, based on the findings, apart from individual's self-concept reported by Ruan ( 2013) as a variable affecting person knowledge students' beliefs and opinions regarding the act of composing is part of person knowledge. Thus, it can be assumed that students' beliefs regarding what effective writing is affects their metacognitive awareness.

Findings of regulation of cognition indicate that regulatory skills of planning and drafting, monitoring, evaluation, and revision which can be found in almost all accounts of regulation of cognition (Schraw, 1998), appear in the reports of Iranian EFL learners. Besides, some general on-line strategies, an extra component which could not be attributed specifically to one of the above-mentioned skills, emerged. We assume that these strategies were in progress almost at any stage of writing and influenced writers' choice of the strategies. For example, if students felt that they did not have enough time, they did not revise their papers or changed the type of planning from written to mental.

\section{Conclusion}

A measure of metacognition in FL learning may also contribute to a better understanding of the nature of metacognition in a domain-specific area as FL writing. Thus, the presented model may partly inform research in the area of metacognition. Furthermore, implementation of metacognitive awareness in EFL courses is greatly in need of a framework to understand the nature of metacognition in this regard. Accordingly, the designed model may help teachers raise their awareness regarding the variables influencing metacognitive awareness in writing. Additionally, the results of the study are significant because research on metacognition in writing is heavily dependent on valid measuring instruments to assess metacognitive ability. As such, the findings can contribute to the development of a measure of metacognitive awareness in EFL writing. 


\section{References}

Bandura, A. (1982). Self-efficacy mechanism in human agency. American Psychologist, 37, 122- 147. http://dx.doi.org/10.1037/0003-066X.37.2.122

Becker, A. (2006). A review of writing model research based on cognitive process. A. Horning \& A. Becker (Eds.), Revision: History, theory, and practice (pp. 24-49). West Lafayette, IN: Parlor Press.

Bernat, E., \& Gvozdenko, I. (2005). Beliefs about language learning: Current knowledge, pedagogical implications, and new research directions. TESL-EJ, 9(1), 1-21.

Brown, A. L., Bransford, J. D., Ferrara, R. A., \& Campione, J. C. (1983). Learning, remembering, and understanding. In P. H. Mussen (Ed.), Handbook of child psychology (4 ${ }^{\text {th }}$ ed., Vol. III, pp. 77-166). New York: Wiley.

Cary, M., \& Reder, L. M. (2002). Metacognition in strategy selection: Giving consciousness too much credit. In P. Chambres, M. Izaute, \& P. J. Marescaux (Eds.), Metacognition: Process, function, and use (pp.63-78). New York, NY: Kluwer. http://dx.doi.org/10.1007/978-1-4615-1099-4_5

Chuenchaichon, Y. (2011). Impact of intensive reading on the written performance of Thai university EFL writers. Language Studies Working Papers, 3, 3-14.

Flavell, J. H. (1979). Metacognition and cognitive monitoring: A new area of cognitive-developmental inquiry. American Psychologist, 34, 906-911. http://dx.doi.org/10.1037/0003-066X.34.10.906

Flavell, J. H. (1987). Speculation about the nature and development of metacognition. In F. Weinert \& R. Kluwe (Eds.), Metacognition, motivation, and understanding (pp. 21-29). Hillsdale, NJ: Lawrence Erlbaum.

Gunstone, R. F. (1994). The importance of specific science content in the enhancement of metacognition. In P. Fensham, R. Gunstone, \& R. Whit (Eds.), The content of science: A constructivist approach to its teaching and learning (p.131-146). London: Flamer Press.

Hacker, D. J., Keener, M. C., \& Kircher, J. C. (2009). Writing is applied metacognition. In D. J. Hacker, J. Dunlosky \& A. C. Graesser (Eds.), Handbook of metacognition in education (pp. 154-172). New York: Routledge.

Harris, K. R., Santangelo, T., \& Graham, S. (2010). Metacognition and strategies instruction in writing. In H. S. Waters \& W. Schneider (Eds.), Metacognition, strategy use, and instruction (pp. 226-256). New York: London: The Guilford Press.

Hayes, J., \& Flower, L. (1980). Identifying the organization of writing processes. In L. Gregg \& E. Steinberg (Eds.), Cognitive processes in writing (pp. 3-30). Hillsdale, NJ: Erlbaum.

Hawkins, R. E. (2007). Classifying and characterizing student writers' metacognition: A social cognitive ethnography (Doctoral dissertation). Available at http://books.google.com

Jacobs, J. E., \& Paris, S. G. (1987). Children's metacognition about reading: Issues in definition, measurement, and instruction. Educational Psychologist, 22, 225-278.

Jacobs, H. L., Zinkgraf, S. A., Wormuth, D. R., Hartifiel, V. G., \& Haughey, J. B. (1981). Testing ESL composition: A practical approach. Rowley, MA: Newbury House Publishers. http://dx.doi.org/10.1080/00461520.1987.9653052

Kasper, L. F. (1997). Assessing the metacognitive growth of ESL student writers. TESL EJ, 3(1), 1-20.

Kietlinska, K. (2006). Revision and ESL students. In A. Horning \& A. Becker (Eds.), Revision: history, theory, and practice (pp. 63-87). USA: Parlor Press and The WAC Clearing House.

Leonardi, V. (2010). The role of pedagogical translation in second language acquisition. Bern: Peter Lang Publishing.

Manchón, R. M., \& Roca de Larios, J. (2007). On the temporal nature of planning in L1 and L2 composing. Language Learning, 57, 549-593. http://dx.doi.org/10.1111/j.1467-9922.2007.00428.x

McKeown, M. G., \& Beck, I. L. (2009). The role of metacognition in understanding and supporting reading comprehension. In D. J. Hacker, J. Dunlosky, \& A. C. Graesser (Eds.), Handbook of metacognition in education. The educational psychology series (pp. 7-25). Mahwah, NJ: Lawrence Erlbaum Associates.

$\mathrm{Mu}, \mathrm{C}$. (2005). A taxonomy of ESL writing strategies. In Proceedings redesigning pedagogy: Research, policy, practice. Singapore. 
Maftoon, P., Birjandi, P., \& Farahian, M.

Negretti, R. (2012). Metacognition in student academic writing: A longitudinal study of metacognitive awareness and its relation to task perception and evaluation of performance. Written Communication, 29(2), 142-179. http://dx.doi.org/10.1177/0741088312438529

Newman, R. S. (1998). Adaptive help seeking: A role of social interaction in self-regulated learning. In S. A. Karabenick (Ed.), Strategic help seeking: Implications for learning and teaching. (pp. 13-37). Hillsdale, NJ: Erlbaum

O'Malley, J. M., \& Chamot, A. U. (1990). Learning strategies in second language acquisition. Cambridge: Cambridge University Press. http://dx.doi.org/10.1017/CBO9781139524490

Pintrich, P. R. (2002). The role of metacognitive knowledge in learning, teaching, and assessing. Theory into Practice, 41(4), 219-225. http://dx.doi.org/10.1207/s15430421tip4104_3

Riazi, A. (1997). Acquiring disciplinary literacy: A social-cognitive analysis of text production and learning among Iranian graduate students of education. Journal of Second Language Writing, 6(2), 105-137. http://dx.doi.org/10.1016/S1060-3743(97)90030-8

Roca de Larios, J., Murphy, L., \& Marín, J. (2002). A critical examination of L2 writing process research. In S. Ransdell \& M. L. Barbier (Eds.), New directions for research in L2 writing (Vol. 11, pp. 11 - 47): Kluwer Academic Publishers. http://dx.doi.org/10.1007/978-94-010-0363-6_2

Ruan, Z. (2014). Metacognitive awareness of EFL student writers in a Chinese ELT context. Language Awareness, 23(1-2), 76-91. http://dx.doi.org/10.1080/09658416.2013.863901

Sasaki, M. (2002). Building an empirically-based model of EFL learners' writing processes. In Ransdell, S. and M. L. Barbier (Eds.), New directions for research in L2 writing (pp. 49-80). Dordrecht: Kluwer Academic. http://dx.doi.org/10.1007/978-94-010-0363-6_3

Schraw, G. (1998). Promoting general metacognitive awareness. Instructional Science, 26, 113-125. http://dx.doi.org/10.1023/A:1003044231033

Schraw, G., \& Dennison, R. S. (1994). Assessing metacognitive awareness. Contemporary Educational Psychology, 19, 460-475. http://dx.doi.org/10.1006/ceps.1994.1033

Schraw, G., \& Moshman, D. (1995). Metacognitive theories. Educational Psychology Review, 7(4), 351-371. http://dx.doi.org/10.1007/BF02212307

Sun, R., \& Mathews, R. (2002). Explicit and implicit processes of metacognition. In S. P. Shohov (Ed.), Advances in Psychology Research (Vol. 18, pp. 3-13). Hauppauge, NY: Nova Science Publishers.

Tarricone, P. (2011). The taxonomy of metacognition. New York: Psychology Press.

Tsang, W.-K. (1996). Comparing the effects of reading and writing on writing performance. Applied Linguistics, 17(2), 210-233. http://dx.doi.org/10.1093/applin/17.2.210

Yu-Ling, Y., \& Shih-Guey, J. (2001). Investigating the metacognitive awareness and strategies of English-majored university student writers. Retrieved from http://files.eric.ed.gov/fulltext/ED465281.pdf

Vanderswalmen, R., Vrijders, J., \& Desoete, A. (2010). Metacognition and spelling performance in college students. In A. Efklides \& P. Misailidi (Eds.), Trends and prospects in metacognition research (pp. 367-394). Springer, NY: New York.

Victori, M. (1999). An analysis of writing knowledge in EFL composing: A case study of two effective and two less effective writers. System, 27, 537-555. http://dx.doi.org/10.1016/S0346-251X(99)00049-4

Wenden, A. L. (1998). Metacognitive knowledge and language learning. Applied Linguistics, 19(4), 515-537. http://dx.doi.org/10.1093/applin/19.4.515

Wenden, A. (1999). An introduction to metacognitive knowledge and beliefs in language learning: Beyond the basics [Special Issue]. System, 27, 435-441. http://dx.doi.org/10.1016/S0346-251X(99)00043-3

Wong, B. Y. L. (1991). The conceptual perspectives in the connections between reading and writing processes. In A. McKeough \& J. L. Lupart (Eds.), Toward the practice of theory-based instruction. Current cognitive theories (p. 66-93). Hillsdale, NJ: Lawrence Erlbaum.

Zimmerman, B., \& Risemberg, R. (1997). Becoming a self-regulated writer: A social cognitive perspective. Contemporary Educational Psychology, 22, 73-101. http://dx.doi.org/10.1006/ceps.1997.0919 


\section{Appendix}

Interview Questions:

\section{Knowledge of cognition}

1. What is your general attitude toward writing? Do you think you are a good writer in English?

2. How do you feel when you are assigned a writing task in English? Do you enjoy it? Why (not)?

3. What kind of problems do you often encounter while writing in English? What is the main one? How do you deal with your problems?

4. Are you familiar with English writing conventions (for example how to write a topic sentence, how to compose a paragraph, how to establish cohesion and coherence)? Are you aware of them while writing in English?

5. Do you know how to begin, proceed and conclude the writing task? Explain a bit.

6. Are you aware of the strategies you use while writing? Do you have specific reasons for using them?

7. If you use specific strategies, when and why you use them. How do you apply the strategies to your writing?

\section{Regulation of cognition}

1. What do you do first before you begin to write in English? Do you have any plan in your mind before beginning to write? Explain a bit.

2. Do you try to concentrate first on the overall idea, the audience, and the message before you begin to write?

3. What do you hope to accomplish with what you write? (Satisfy the teacher? Be able to write emails?) Do you set goals and sub-goals before and while writing?

4. While writing in English, what do you do when you have a problem and get stuck? Do you consider several alternatives to the problem?

5. Do you often stop while writing and ask yourself how well you are doing? What do you do then?

6. What do you do when you finish writing? Do you know how well you have done when you finish the task?

7. Do you often revise your writing tasks?

8. Do you stop while writing and reread what you have written?

9. What do good writers do?

10. Is there anything else you would like to add about your writing in English? 
Maftoon, P., Birjandi, P., \& Farahian, M. 